\title{
Desempenho no Enade de bolsistas ProUni: Modelagem de Equações Estruturais
}

\author{
Claudette Maria Medeiros Vendramini, ^ Fernanda Luzia Lopes \\ Universidade São Francisco
}

\begin{abstract}
Resumo
Esse estudo objetivou investigar o desempenho no Enade de estudantes bolsistas do Programa Universidade para Todos - ProUni da própria instituição e de estudantes com outros tipos de bolsas e, ainda investigar, por meio de Modelos de Equações Estruturais, se este desempenho se mantém para estudantes sob a condição de ingressantes e concluintes. Utilizou-se um banco de dados contendo os resultados de 401.117 estudantes que realizaram o exame do Enade em 2006, composto pelas provas de Formação Geral e de Conhecimento Especifico. O mesmo modelo de equações estruturais foi utilizado para analisar os dados de estudantes ingressantes e concluintes. Os resultados obtidos indicaram que o modelo de mensuração dos estudantes bolsistas com relação às notas do Enade apresenta um ajuste razoavelmente bom e permite afirmar que o desempenho do estudante durante a graduação é inferior ao do momento de seu ingresso no Ensino Superior.
\end{abstract}

Palavras-chave: ensino superior; métodos estatísticos; avaliação em larga escala.

\section{ProUni Scholar students performance in Enade: Structural Equations Modeling}

\begin{abstract}
This study aimed to investigate the performance in the National Students Exam-Enade of students with scholarships ProUni ("University for all" Programme), with grants of the education institutions themselves and students with other types of scholarships, and also to investigate, through the Structural Equation Modeling, whether this performance is maintained under the conditions of freshmen and seniors. We used a database containing the results of 401,117 students who took the Enade exam in 2006, which is composed both of the General Formation and the Specific Knowledge tests. The same structural equation model was used to analyse the database of freshmen and seniors students. The obtained results indicated that the measurement model of the scholar students concerning the Enade grades provides a reasonably good fit and allows us to say that the student's performance through graduation is poorer than the moment of their admission to College.
\end{abstract}

Keywords: higher education; statistical methods; large scale assessment.

\section{Introdução}

O Programa Universidade para Todos (ProUni) foi instituído em setembro de 2004, com o objetivo de conceder bolsas de estudos parciais e integrais a estudantes que preencham os requisitos solicitados na ocasião de sua criação. Esses requisitos indicam que o estudante, para pleitear uma bolsa de estudos, deve possuir renda per $\mathrm{ca}_{-}$ pita familiar de um salário mínimo e meio para bolsas integrais e três salários mínimos para as bolsas parciais de $50 \%$ (os professores da rede pública não necessitam atender esse critério), ter cursado o Ensino Médio completo na rede pública de ensino ou ter cursado o Ensino Médio na rede particular na condição de bolsista integral, apresentar algum tipo de deficiência nos termos da lei ou ser professor da rede pública de ensino (BRASIL, 2004a).

Por outro lado, as Instituições de Ensino Superior (IES) que aderem ao ProUni estão isentas do Imposto de Renda de Pessoas Jurídicas, da Contribuição social sobre o Lucro Líquido, da Contribuição Social para Financiamento da Seguridade Social e da Contribuição para o Programa de Integração Social (BRASIL, 2004a). Assim, o ProUni surgiu como um incentivo do Governo Federal aos alunos que não podem custear seus estudos numa universidade privada e, desde sua implementação,

\footnotetext{
* Endereço para correspondência: Universidade São Francisco, - Campus Itatiba. Rua Alexandre Rodrigues Barbosa, 45 - Centro. CEP: 13251-900 - Itatiba, SP Brasil.E-mail: cvendramini@uol.com.br, fernandallopes@hotmail.com
}

contemplou aproximadamente 1,5 milhões de estudantes, sendo $70 \%$ deles com bolsas integrais (PROUNI). De acordo com o Ministério da Educação (MEC), desde sua criação até o ano de 2011, o Programa já formou 174,5 mil estudantes (PROUNI).

Dentre os critérios já mencionados para o pleito da bolsa de estudo parcial ou integral ofertada pelo Programa, está o critério nota no Exame Nacional do Ensino Médio - Enem. A Portaria número 3.964 de 2 de dezembro de 2004 definia que o estudante com interesse em concorrer a uma bolsa de estudos para o ano letivo de 2005 deveria ter participado da edição do Enem no ano de 2004 em que a nota total seria composta pela média aritmética entre as notas obtidas pelo candidato nas provas de conhecimento e redação do Enem (BRASIL, 2004b).

No ano de 2006, um novo critério foi determinado para os estudantes que buscavam uma bolsa de estudos por meio do ProUni para o ano letivo de 2007. A Portaria número 1.853 de 28 de novembro de 2006 determinou uma nota de corte mínima para a participação do estudante no processo seletivo. Sendo assim, os estudantes que obtivessem notas inferiores a 45 pontos, estariam vetados de participarem do processo (BRASIL, 2006).

Críticas ao ProUni vêm sendo tecidas principalmente no que concerne aos investimentos na educação pública. Nesse sentido, destaca-se a pesquisa de Saraiva e Nunes (2011), cujo objetivo foi compreender a efetividade do 
programa a partir da avaliação dos beneficiados - bolsistas ProUni. Os resultados indicaram que, na opinião dos bolsistas, o programa atende as expectativas quanto à inclusão no ensino superior, bem como à perspectiva de sucesso profissional. Contudo, os autores enfatizam que a efetividade do programa esbarra na necessidade da maior instrumentalização de recursos para a qualidade e abrangência da educação superior pública.

Na Gráfico 1 é possível visualizar o número de bolsas distribuídas por ano, desde a criação do Programa até o ano de 2014. De acordo com o gráfico a seguir, pode-se observar um aumento gradativo no número de concessão de bolsas de estudos integrais e parciais em cada ano de edição do ProUni.

$$
\begin{aligned}
& \text { Fonte: http://prouniportal.mec.gov.br/images/pdf/Representacoes_graficas/ } \\
& \text { bolsas_ofertadas_ano.pdf }
\end{aligned}
$$

de tarefas, testes ou exames acadêmicos. Assim, a habilidade estaria associada à performance ou algum tipo de potencial de execução (CARROLL, 1993).

O modelo mais conhecido de habilidades cognitivas é proposto por Carroll (1992; 1993), baseado numa meta-análise de artigos e trabalhos sobre o tema além do aperfeiçoamento das teorias de Cattell e Horn, que culminou na Teoria dos Três Estratos da Inteligência, também conhecido por modelo CHC. Esse modelo considera que as habilidades cognitivas podem ser descritas em três camadas ou estratos organizados hierarquicamente, em que o Estrato III é composto pelo fator $g$, o mais abrangente, $o$ Estrato II composto por 10 fatores gerais que influenciam uma gama de capacidades e, por fim, o Estrato I, combinado por um conjunto de habilidades intermediárias.

Ackerman e Rolfhus (1999) enfatizam que alguns pesquisadores impõem o bom desempenho na resolução de tarefas e tomadas de decisões aos fatores $G c$ (inteligência cristalizada) e $G f$ (inteligência fluida) - para esses autores, esse modo de se pensar a inteligência é uma maneira pobre de se avaliar a abrangência intelectual em adultos. Diante desta premissa, Rolfhus e Ackerman (1999) propuseram uma teoria da inteligência que introduz o domínio do conhecimento específico como parte in-

Nas últimas edições do ProUni, as notas de corte têm sido variadas de acordo com a área, o curso e o turno pretendido pelo estudante. As áreas da saúde, como Medicina e Enfermagem, tendem a ser mais concorridas e exigem maiores notas no Exame. Sendo assim, a nota no Enem se apresenta como uma pré-seleção em que o estudante já ingressa no Ensino Superior, na condição de bolsista ProUni, com um desempenho melhor que seus pares.

Sendo assim, o desempenho acadêmico do estudante ProUni, ao menos é esperado, dever ser semelhante aos estudantes que ingressaram na IES sob outras condições (vestibular, entrevistas, entre outros) e se manter assim ao longo da graduação. Desta maneira, averiguar o desempenho acadêmico dos estudantes bolsistas e estudantes não-bolsistas, em âmbito nacional, torna-se relevante, não somente, para o contexto socioeducacional mas também, às vertentes psicológicas que estudam a relação entre o desempenho acadêmico e as teorias da inteligência.

O conceito de desempenho abarca a interface entre Psicologia e Educação, e está associado a variáveis representativas de cada uma dessas áreas do saber. No que concerne à Psicologia, o desempenho acadêmico no contexto das avaliações em larga escala, pressupõe habilidades cognitivas necessárias ao sucesso na realização tegrante da inteligência em adultos. Esse conhecimento específico exerce importante papel no desempenho intelectual e pode ser atribuído, principalmente, aos níveis mais elevados e integrados do conhecimento (ROLFHUS; ACKERMAN, 1999).

Diante destes estudos, McGrew (2008) indica uma lacuna significativa no modelo $\mathrm{CHC}$ e apresenta a inclusão de seis grandes fatores e domínios referentes às habilidades cognitivas, dentre eles a $G k n$. A $G k n$ refere-se ao domínio do conhecimento específico e reflete habilidades especializadas do conhecimento desenvolvido por um longo período de tempo e que exige intensa prática e formação, cuja conservação do conhecimento é determinada pela regularidade e interesse. Essa habilidade ou domínio estaria mais associado ao bom desempenho em testes e provas acadêmicas (ACKERMAN; LOHMAN, 2006; MCGREW; EVANS, 2004; MCGREW, 2008).

Rolfhus e Ackerman (1999) indicam que o conhecimento específico está diretamente associado ao Gc. A principal distinção entre $G c$ e $G k n$, conforme Ackerman e Lohman (2006) e McGrew e Evans (2004), reside no fato de que a $G c$ reflete, principalmente, o conhecimento geral acumulado por meio da experiência do sujeito em determinada cultura enquanto que, a $G k n$ representa a amplitude e 
a profundidade do conhecimento em domínios específicos. Assim, o fator $G k n$ estaria mais associado ao desempenho em, por exemplo, testes e provas acadêmicas.

Ainda sobre habilidades cognitivas, Brito (2008) enfatiza que as provas do Enade, composta por 10 questões de Formação Geral e 30 questões de Conhecimento Específico, têm por objetivo mensurar as habilidades acadêmicas e as competências profissionais de cada área avaliada. Para a autora, as habilidades acadêmicas dizem respeito a capacidade do sujeito na realização de tarefas, solucionar problemas, ter sucesso no domínio das exigências do meio etc. Assim dito, a habilidade acadêmica pode estar mais relacionada aos fatores da inteligência $G c$ e $G f$.

A competência profissional, segundo Brito (2008), está mais associada à capacidade de articulação dos conhecimentos adquiridos e sua eficácia nas atividades solicitadas pela natureza do trabalho o que, no Enade, corresponderia ao conhecimento exigido no componente de Conhecimento Específico. Assim colocada, a competência profissional pode ter maior associação com o fator da inteligência $G k n$, proposto por McGrew (2008).

$\mathrm{Na}$ literatura especializada são escassas as publicações cujos propósitos sejam comparar o desempenho entre estudantes contemplados com bolsas de estudos e estudantes pagantes de IES privadas. Nesse sentido, pode-se citar os estudos apresentados pelo Inep (BRASIL, 2009) e por Lopes, Vendramini e Mata (2009). O estudo publicado pelo Inep (BRASIL, 2009) teve por objetivo comparar o desempenho acadêmico de estudantes com bolsas ProUni e estudantes pagantes que realizaram o Enade no ano de 2007. O critério utilizado foi considerar apenas os cursos que tivessem, entre seus ingressantes e concluintes, bolsistas ProUni, totalizando a amostra de 70.269 estudantes. Os resultados indicaram que os estudantes ingressantes de todas as áreas avaliadas pelo Enade 2007, obtiveram notas maiores que os alunos não-bolsistas. Já para os estudantes concluintes houve diferenças estatisticamente significativas entre bolsistas e não-bolsistas apenas nas áreas de Biomedicina e Tecnologia em Radiologia.

O estudo de Lopes, Vendramini e Mata (2009) teve por objetivo verificar se o desempenho de estudantes do ensino superior no Enade de Psicologia em 2006 diferia entre grupos de estudantes com diferentes tipos de bolsas. As autoras utilizaram um banco de dados contendo informações de 23.613 estudantes de Psicologia de todos os estados brasileiros que realizaram o Enade no ano de 2006 , sendo $54,8 \%$ ingressantes. Os resultados indicaram que as médias das notas dos estudantes nas provas componentes do Enade/2006 (prova de Formação Geral e prova de Conhecimento Específico) com bolsas parciais ou integrais (ProUni), da própria instituição ou de entidades externas, foram maiores que a média do desempenho acadêmico dos estudantes que não contam com nenhum tipo de bolsa, tanto no grupo dos ingressantes quanto no grupo dos concluintes. A limitação deste estudo reside no fato das pesquisadoras não estabelecerem uma relação entre a diferença de desempenho entre os alunos ingres- santes e concluintes. Cabe ressaltar que, até o momento, não foram encontrados estudos, nas bases eletrônicas, que mencionassem essa diferença entre os estudantes.

No estudo realizado por Lira (2010) com 301 estudantes com e sem bolsa ProUni o autor constatou que bolsistas ProUni apresentavam desempenho superior a de outros alunos que não receberam esta modalidade de bolsa. Esses resultados corroboram os encontrados por Lopes, Vendramini e Mata (2009).

Nos últimos anos, com o boom universitário, a criação do próprio ProUni e de outros Programas que atendam uma demanda mais carente da população, facilitou o acesso dos estudantes à universidade. Assim, torna-se importante conhecer esse estudante no momento que ingressa na universidade e no momento em que está finalizando esse processo, já que esse fenômeno não é puramente social, mas pode refletir a temática educacional e suas implicações para o contexto. Uma maneira de se averiguar o desempenho desses estudantes é por meio do Enade, um dos instrumentos que integram o Sistema Nacional de Avaliação da Educação Superior (Sinaes), instituído em abril de 2004, pela Lei no 10861 (BRASIL, 2004c). O objetivo do Sinaes é averiguar, em âmbito nacional, a qualidade das instituições de nível superior, dos cursos de graduação das diversas áreas do conhecimento e o desempenho dos estudantes e, ainda, o perfil social e econômico desses estudantes.

Assim, a investigação sugerida pelo Enade, desde sua primeira edição em 2004, utiliza-se de quatro instrumentos, quais sejam, a prova, composta por itens que pretendem aferir o desempenho de estudantes com relação aos conteúdos programáticos a que se inserem, bem como conhecimentos em outras áreas; o questionário de impressões sobre a prova, que tem por objetivo verificar a percepção do estudante referente a aspectos específicos da prova como, por exemplo, nível de dificuldade, tempo de realização, entre outros; questionário de perfil do estudante cujo propósito é compor o perfil do estudante, com informações acerca de suas vivências dentro da IES; e, o questionário do coordenador do curso, que se propõe a buscar informações dos profissionais sobre aspectos da prova e suas relações com o projeto pedagógico, além das condições gerais de ensino em seus cursos de graduação (BRASIL, 2005).

Considerando o exposto, este estudo teve por objetivo investigar as possíveis diferenças de desempenho no Enade de alunos com bolsas ProUni, em relação aos estudantes com bolsas da própria instituição, estudantes com outros tipos de bolsas e estudantes que não possuem nenhum tipo de bolsa e, ainda, investigar se este desempenho se mantém nas condições de estudantes ingressantes e concluintes. Cabe ressaltar que, o atual sistema de avaliação do Ensino Superior, não permite a utilização de dados longitudinais, dado a inexistência dessa metodologia, mas permite que, por meio do Enade se possa investigar o desempenho dos estudantes no mesmo ano e em suas carreiras pretendidas. 


\section{Método}

\section{Banco de dados}

Foi utilizado um banco de dados contendo os resultados de 401.117 estudantes, divididos em 214.579 ingressantes e 186.538 concluintes, de ambos os sexos, que realizaram a prova do Enade no ano de 2006 em que se contemplaram os seguintes cursos: Administração, Arquivologia, Biblioteconomia, Biomedicina, Ciências Contábeis, Ciências Econômicas, Comunicação Social, Design, Direito, Música, Normal Superior, Psicologia, Secretariado Executivo, Teatro e Turismo.

\section{Material}

Considerando o fato de que segundo Ackerman e Rolfhus (1999) e McGrew e Evans (2004) o conhecimento geral é refletido pela inteligência cristalizada $(G c)$ que estão diretamente associada à profundidade do conhecimento específico segundo Ackerman e Lohman (2006) e McGrew e Evans (2004), e ainda que as habilidades cognitivas são necessárias ao sucesso na realização de testes e exames acadêmicos (CARROLL, 1993) escolheu-se como material de avaliação de desempenho a prova do Enade realizado em 2006. Cabe observar que a prova do Enade foi composta por 40 questões no formato discursivo e objetivo de múltipla escolha, sendo que 10 são de avaliação de conhecimentos gerais - a prova de Formação Geral (FG); e, por 30 questões específicas da área referentes à parte do Componente Específico (CE). A prova de FG é comum a todos os cursos e tem por objetivo investigar a formação de um profissional ético e comprometido com a sociedade, bem como aferir o domínio de conhecimentos diversificados de habilidades acadêmicas e competências profissionais. Já o CE de cada área do conhecimento é elaborado com base nas Diretrizes Curriculares Nacionais (DCN), aprovadas pelo Conselho Nacional de Educação (CNE) e no perfil profissional de cada carreira, levando em consideração os saberes fundamentais em cada área profissional (BRASIL, 2005). Destaca-se que o número de questões dissertativas difere por curso e por ano de edição do Enade.

\section{Análise dos dados}

A Modelagem Equações Estruturais (MEE) foi utilizada como o objetivo de avaliar simultaneamente uma série de equações que envolvem inter-relações entre variáveis, especificadas em um modelo orientado pela combinação de elementos teóricos sobre habilidades cognitivas necessárias para um bom desempenho em provas e testes educacionais (CARROLL, 1993; ACKERMAN; ROLFHUS, 1999; MCGREW; EVANS, 2004; ACKERMAN; LOHMAN, 2006) e evidências empíricas de pesquisas anteriores que constataram que o desempenho de bolsistas ProUni ou de outra modalidade apresentam melhor desempenho que outros estudantes quando avaliados quanto ao conhecimento geral e específico de uma área de conhecimento (LIRA, 2010; LOPES; VENDRAMINI; MATA, 2009). A MEE exige um número amostral maior que outras técnicas estatísticas, devido à avaliação simultânea de várias relações entre as variáveis, porém vale ressaltar que a discussão dos resultados foi baseada em diferentes indicadores objetivando corrigir distorções quanto ao tamanho amostral desta pesquisa.

$\mathrm{O}$ modelo de equações estruturais MEE foi avaliado por meio do software estatístico AMOS, em sua $16^{\mathrm{a}}$ versão, com o emprego do método de máxima verossimilhança. Foram utilizados quatro índices para a análise do ajuste do modelo, conforme as recomendações da literatura pertinente (BYRNE, 2001; SCHWEIZER, 2010). Faz parte desses índices o valor do Qui-quadrado $\left(\chi^{2}\right)$ que indica a magnitude da discrepância entre a matriz de covariância observada e a modelada, em que altos valores advertem desajuste do modelo; Contudo, o Qui-quadrado é afetado pelo tamanho da amostra, como é o caso deste modelo, assim, recomenda-se utilizar o índice Qui-quadrado dividido pelos graus de liberdade denominado CMIM que, quando menor que 2, consiste em um indicativo de bom ajuste. O CFI (Comparative Fit In$d e x$, outro índice para ajuste do modelo, calcula o ajuste relativo do modelo ao compara-lo com o modelo nulo, cujas variáveis possuem correlação zero entre si, em que valores acima de 0,95 indicam bom ajuste do modelo. O índice RMSEA (Root-Square Error of Aproximation) é um índice de ajuste absoluto, assim, valores menores que 0,05 revelam bom ajuste. Por último, o índice SMR (Standardized Root Mean Square Residual) reporta a média padronizada dos resíduos (discrepâncias entre a matriz observada e modelada) cujos valores indicativos de bom ajuste devem ser menores que 0,10 (BYRNE, 2001; SCHWEIZER, 2010).

\section{Resultados e discussão}

O uso do MEE vem sendo cada vez mais utilizado por pesquisadores da área de Psicologia. Esse modelo admite o teste confirmatório da estrutura psicométrica e, ainda, pode ser utilizada quando o intuito da pesquisa é analisar relações explicativas, simultaneamente, entre múltiplas variáveis que podem ser latentes ou observadas (PILATI; LAROS, 2007). Assim sendo, a MEE possibilita ao pesquisador testar o grau em que o padrão das cargas fatoriais pode representar os dados reais (HAIR et al., 2011).

Para atingir o objetivo proposto para este estudo, por meio da MEE, foi considerado o banco de dados que contempla as respostas dos estudantes nas provas de Formação Geral e de Conhecimento Específico do Enade 2006 dividido em dois grupos, a saber, estudantes ingressantes e estudantes concluintes. Feita esta divisão, o banco de dados passou por mais uma subdivisão no que concerne aos alunos bolsistas, em que se criou três novas variáveis para cada tipo de bolsa, a saber, bolsistas ProUni, bolsistas da própria instituição e estudantes com bolsas de estudos proveniente de outras instituições. Dessa maneira, o critério para a criação da variável "bolsistas ProUni" foi considerar o valor " 1 " para os estudantes com este tipo de bolsa e " 0 " para os estudantes que não apresentavam nenhum tipo de bolsa (critério: 100 e 010 ). Este critério foi utilizado para a criação das três variáveis e permitiu que, a partir desta subdivisão, se pudesse comparar o desempenho entre os estudantes com bolsas de estudo e 
aqueles que não possuíam nenhum tipo de bolsa. O mesmo modelo (figuras 1 e 2) foi utilizado para as análises nos dois grupos de estudantes.

O MEE utilizado para este estudo apresentou parâmetros que indicaram um ajuste razoável aos dados. Os resultados obtidos indicaram os seguintes índices de ajuste, para o $\chi^{2}$ o valor foi de 29.090, 31 com 22 graus de liberdade $(d f)$, o CMIN cuja medida se refere ao valor do $\chi^{2}$ dividido pelos graus de liberdade foi de 1322,287 . Conforme recomendações da literatura pertinente (BYRNE, 2001; SCHWEIZER, 2010), esse valor, para indicar um bom ajuste, deve ser menor que 2,0. Contudo, tal valor pode ser afetado pelo tamanho da amostra que, para este estudo, considerou mais de 400 mil observações, assim, outros índices de ajuste foram calculados para verificar o ajuste do modelo.

$\mathrm{O}$ índice RMSEA, indicativo de ajuste absoluto, atingiu o valor de 0,052 . O valor de referência para esta medida é de 0,05 (BYRNE, 2001; SCHWEIZER, 2010), o que indica que o modelo em questão apresenta um ajuste, marginalmente, bom. Outro resultado que sustenta este modelo é a medida CFI, que se refere ao índice de ajuste incremental, cujo valor foi de 0,964, maior que o índice de referência que é de 0,95 . Já para a medida SMR o resultado obtido foi igual a 0,0232 , menor que o valor máximo de referência $(0,10)$. Sendo assim, esses resultados sugerem que o modelo de mensuração dos estudantes bolsistas com relação às notas do Enade apresentou um ajuste razoavelmente bom de acordo com as recomendações da literatura pertinente (BYRNE, 2001; SCHWEIZER, 2010).

Esses resultados também são corroborados com os apresentados por Pilati e Laros (2007), que bem resumem os indicadores de adequação dos modelos classificados por Ullman (2007) em cinco categorias, a primeira que contempla os índices comparativos e compara o $\chi^{2} \mathrm{de}$ modelos independentes com o $\chi 2$ do modelo em teste, e podem ser expressos por diferentes índices, entre eles o CFI (Comparative Fit Index), que de acordo com a literatura indica bom ajuste quando for superior a 0,95 (ULLMAN, 2007) e o RMSEA (RootMean Square Error of Approximation) considerado adequado quando seu valor for menor do que 0,08 , dado o poder do teste (HANCOCK; FREEMAN, 2001; MACCALLUM; BROWNE; SUGAWARA, 1996, apud PILATI; LAROS, 2007 )

As figuras 1 e 2 e a Tabela 1 representam o modelo composto pelo fator ENADE e suas variáveis medidas a nota total na parte objetiva do componente de Formação Geral (NtObFG), a nota total na parte discursiva do componente de Formação Geral (NtDisFG), a nota total na parte objetiva do componente de Conhecimento Específico (NtObCE) e a nota total na parte discursiva do componente de Conhecimento Específico (NtDisCE). As variáveis dos estudantes referem-se aos Bolsistas ProUni (ProUni) que contemplaram os estudantes com bolsas integrais $(100 \%)$ e com bolsas parciais $(50 \%)$, os estudantes que receberam bolsas de estudos da própria IES (Bolsa Instit) e, por fim, os estudantes que receberam outros tipos de bolsas de estudos (Bolsa_Outr).

Fractal, Rev. Psicol., v. 28 - n. 1, p. 69-75, 2016

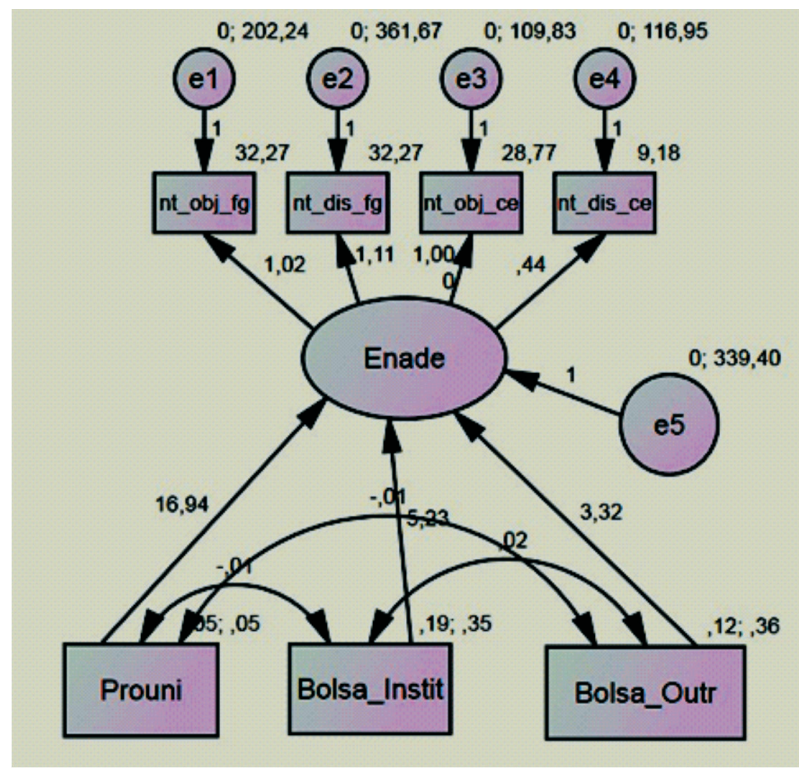

Figura 1 - Modelo de Equações Estruturais dos bolsistas ingressantes e o desempenho no Enade 2006

Conforme as figuras apresentadas, pode-se observar, no caso dos estudantes ingressantes (Figura 1), a incidência de escores de associação mais elevados nas três modalidades de bolsas em relação a esses mesmos escores obtidos pelos estudantes concluintes (Figura 2) dos diversos cursos de graduação avaliados pelo Enade 2006. O mesmo acontece com relação às notas de formação geral em que os escores são maiores também para os estudantes ingressantes, porém iguais ou menores para o componente específico.

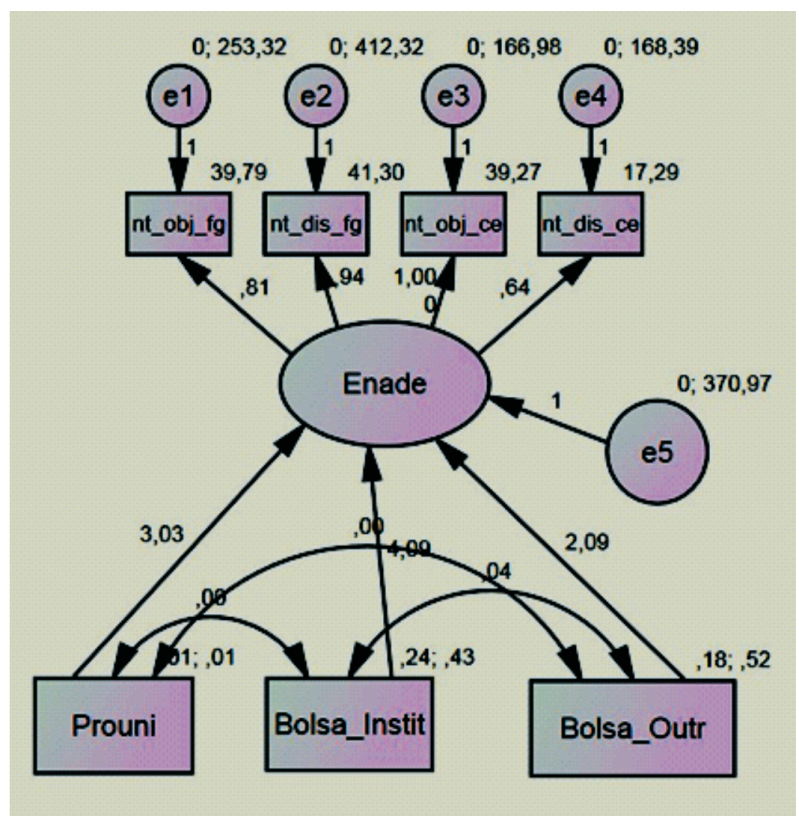

Figura 2 - Modelo de Equações Estruturais dos bolsistas concluintes e o desempenho no Enade 2006

Na Tabela 1 são apresentadas essas estimativas para o grupo dos ingressantes e para o grupo dos concluintes. Os resultados indicam, de acordo com suas estimativas, que os estudantes com bolsas ProUni, na condição de ingressantes, apresentam maiores escores que os seus pares com outros tipos de bolsas de estudo e que os não bolsistas. 
Tabela 1 - Distribuição das Estimativas e Erro padrão da variável latente e de outras variáveis

\begin{tabular}{llccc} 
& \multicolumn{2}{c}{ Ingressantes } & \multicolumn{2}{c}{ Concluintes } \\
\cline { 2 - 5 } Variáveis & Estimativa & Erro-padrão & Estimativa & $\begin{array}{l}\text { Erro- } \\
\text { padrão }\end{array}$ \\
\cline { 2 - 5 } ENADE? PROUNI & 16,945 & 0,177 & 3,034 & \\
ENADE? Bolsa_Inst & 5,235 & 0,640 & 4,090 & 0,710 \\
ENADE? Bolsa_Outr & 3,316 & 0,630 & 2,089 & 0,640 \\
nt_obj_fg? ENADE & 1,018 & 0,002 & 0,806 & 0,003 \\
nt_dis_fg? ENADE & 1,112 & 0,003 & 0,941 & 0,003 \\
\multicolumn{1}{c}{$0,0010,6370,002$} & 1,000 & & 1,000 & \\
nt obj ce? ENADE & & & & \\
,437 & & & & \\
nt dis ce? ENADE & & & & \\
\cline { 3 - 5 }
\end{tabular}

Contudo, para o grupo de concluintes, os estudantes com bolsas adquiridas da própria instituição têm maiores escores com relação aos estudantes com bolsas ProUni e esses maiores escores que os estudantes com outros tipos de bolsa e sem bolsa.

Também é passível de discussão o fato do desempenho dos estudantes ingressantes apresentarem melhores resultados no componente de Formação Geral do Enade. Este componente está mais relacionado, de acordo com Brito (2008), com as habilidades acadêmicas que podem ter sido desenvolvidas durante o ensino médio. Situação diferente acontece com os estudantes concluintes que, no componente de conhecimento específico, apresentaram melhor desempenho. Tal fato leva em consideração as competências necessárias para o exercício da futura profissão, proposta pela autora, em que essa competência deve abonar o estudante com um domínio básico de conhecimentos e a capacidade de articulação desse conhecimento em contexto profissional.

Embora as pesquisas propostas pelo Inep (BRASIL, 2009), Lopes, Vendramini e Mata (2009) e Lira (2010) não tivessem por objetivo final investigar as relações entre bolsistas ProUni e bolsistas de outras instituições de fomento, é possível compreender os resultados desta pesquisa, haja vista o desempenho dos estudantes ProUni no Enade ter alcançado médias maiores que estudantes universitários pagantes. Contudo, tais resultados são a guisa de produzir hipóteses que deem margem a novas investigações que perpassam pelo cenário social e educacional do país.

Nesse sentido, uma hipótese que pode explicar os resultados obtidos neste estudo é que, quando ingressam na Universidade, os bolsistas ProUni passam por uma pré-seleção realizada pelo seu desempenho no Enem. Esta pré-seleção estabelece critérios diferentes para cada ano de edição e para cada curso ou área. Dessa maneira, os resultados permitem afirmar que o aproveitamento do estudante, durante a graduação, é inferior ao momento em que este aluno ingressa no Ensino Superior, talvez pela concentração das atividades acadêmicas voltadas mais aos conteúdos específicos de cada área.

Outra fonte de discussão reside no fato de que estudantes bolsistas ProUni, advindos de um programa recém-criado pelo Governo Federal, que, na maioria, se prepararam para o Enem, experimentam com ansiedade o ingresso em uma IES, e em consequência obtêm um melhor desem- penho no Enade, ao ingressar, certamente, pelo impacto causado por toda sua trajetória para se tornar universitário. Considerando este aspecto, a motivação deve ser levada em consideração, por ser um impulsionador frente a uma expectativa grande. Dessa forma, o ambiente se torna mais favorável para elaborar soluções diante de uma avaliação. $\mathrm{Na}$ fase de conclusão, onde os bolsistas obtiveram notas inferiores aos alunos não bolsistas, e que também, não mantiveram o desempenho obtido no ingresso, manifesta-se um fenômeno contrário. Podem ser apontados alguns motivos para tal resultado, como a desmotivação em relação ao curso escolhido, ou a frustação com a IES, e até mesmo, em relação ao mercado de trabalho.

\section{Considerações Finais}

A consolidação do ProUni como um programa que tem por objetivo facilitar o acesso da estudantes carentes ao ensino superior é indiscutível. Nota-se, pelo número de bolsas oferecidas ao longo de 10 edições, o acréscimo e a extensão de estudantes bolsistas no ensino superior privado. Contudo, críticas tecidas quanto ao programa, mencionam a carência de investimento nas instituições de ensino superior público e de qualidade que também poderiam ser portas de acesso aos estudantes.

As publicações e pesquisas que levem em consideração a situação acadêmica de estudantes bolsistas em estabelecimentos privados do ensino superior são escassas. Não obstante, as parcas publicações que tratem deste contexto revelam que esses estudantes conseguem se inserir no ensino superior e o fazem com um bom desempenho acadêmico.

O estudo do desempenho acadêmico, na sua interface entre Psicometria e Educação, é cerceado pelas teorias da inteligência que, por sua vez, são capazes de inferir as habilidades cognitivas solicitadas em tarefas determinadas. Sendo assim, o uso de modelos estatísticos avançados, permitem a compreensão da realidade que se coloca à frente e traz resultados confiáveis nesse contexto, como é o caso do MEE.

O MEE utilizado para este estudo apresentou parâmetros que indicaram um ajuste razoável ao modelo. A análise das estimativas resultantes deste modelo permite articular que os bolsistas ProUni, quando ingressantes, reflete melhor as notas nas provas do Enade. Já os bolsistas ProUni concluintes determinaram menos o desempenho no Exame com relação aos bolsistas da própria instituição, aos estudantes com outros tipos de bolsas e aos estudantes que não possuem nenhum tipo de bolsa.

Pelos resultados expostos mediante tal método de avaliação, nota-se que há uma ambivalência entre os estudantes em suas distintas origens - bolsistas e não bolsistas, ingressantes e concluintes - e, devido aos diferentes resultados e suas variações dentro da mesma classe, torna-se necessário criar e desenvolver novos métodos para investigar este fenômeno. Também sugere-se novos estudos que complementem os encontros nesta pesquisa, em diferentes áreas de conhecimento, bem como, com menor número amostral, haja vista o efeito do tamanho da amostra nos modelos de equações estruturais. 


\section{Referências}

ACKERMAN, P. L.; ROLFHUS, E. L. The locus of adult intelligence: knowledge, abilities, and nonability traits. Psychology and Aging, [S.1.], v. 14, n. 2, p. 314-330, 1999.

ACKERMAN, P. L.; LOHMAN, D. F. Individual diferences in cognitive function. In: ALEXANDER, P. A.; WINNE, P. H. (Org.). Handbook of educational psychology. New Jersey: Lawrence Eribaum Associates, 2006. p. 139-160.

BRASIL. Presidência da República. Casa Civil. Subchefia para Assuntos Jurídicos. Medida Provisória $n^{\circ} 213$, de 10 de setembro de 2004. Institui o Programa Universidade para Todos - PROUNI, regula a atuação de entidades beneficentes de assistência social no ensino superior, e dá outras providências. 2004a. Disponível em:<http://www.planalto.gov.br/ccivil 03/ ato2004-2006/2004/Mpv/213.htm>. Acesso em: 23 jan. 2012.

BRASIL. Ministério da Educação. Gabinete do Ministro. Portaria número 3.964 de 2 de dezembro de 2004. Dispõe sobre o processo seletivo do Programa Universidade para Todos PROUNI, referente ao primeiro semestre de 2005, e dá outras providências. 2004b. Disponível em: <http://prouniportal.mec. gov.br/legislacao/legislacao-2004/15-portaria-n-3-964-de-2de-dezembro-de-2004?path=legislacao-2004>. Acesso em: 23 set. 2011.

BRASIL. Presidência da República. Casa Civil. Subchefia para Assuntos Jurídicos. Lei no 10.861, de 14 de abril de 2004. Institui o Sistema Nacional de Avaliação da Educação Superior - SINAES e dá outras providências. 2004c. Disponível em: $<$ http://www.planalto.gov.br/ccivil_03/_ato2004-2006/2004/ lei/110.861.htm>. Acesso em: 24 set. 2011.

BRASIL. Ministério da Educação. Gabinete do Ministro. Portaria $n^{\circ} 1.853$ de 28 de novembro de 2006. Diário Oficial da União, 29 nov. 2006. Disponível em: <http://prouniportal.mec. gov.br/legislacao/legislacao-2006/63-portaria-n-1-853-de-28de-novembro-de-2006/file>. Acesso em: 30 set. 2011.

BRASIL. Instituto Nacional de Estudos e Pesquisas Educacionais Anísio Teixeira - Inep. Avaliando o desempenho no ENADE de bolsistas do PROUNI. Na Medida - Boletim de Estudos Educacionais do Inep, v. 1, n. 3, p. 15-18, 2009.

BRASIL. Ministério da Educação. Instituto Nacional de Estudos e Pesquisas Educacionais Anísio Teixeira - Inep. SINAES - Sistema Nacional de Avaliação da Educação Superior: da concepção à regulamentação. Brasília: MEC/INEP, 2005.

BRITO, M. R. F. O Sinaes e o Enade: da concepção à implantação. Avaliação, [S.1.], v. 13, n. 03, p. 841-850, 2008.

BYRNE, B. M. Structural Equation Modeling with AMOS, EQS, and LISREL: Comparative Approaches to testing for the Factorial Validity of a Measuring Instrument. International Journal of Testing, [S.1.], v. 1, n. 1, p. 55-86, 2001.

CARROLL, J. B. Cognitive abilities: The State of the Art. Psychological Science, v. 3, n. 5, p. 266-271, 1992.

CARROLL, J. B. Human cognitive abilities: A survey of factoranalytic studies. New York: Cambridge University Press, 1993.

HAIR, J. F. et al. Análise Multivariada de Dados. Porto Alegre: Artmed, 2011.

HANCOCK, G. R.; FREEMAN, M. J. Power and sample size for the root mean square error of approximation test of not close fit in structural equation modeling. Educational and Psychological Measurement, [S.1.], v. 61, n. 5, p. 741-758, 2001.

Fractal, Rev. Psicol., v. 28 - n. 1, p. 69-75, 2016
PROUNI. Programa Universidade para Todos. Disponível em: $<$ http://prouniportal.mec.gov.br/>. Acesso em: 30 set. 2011

LIRA, Á. M. Avaliação do programa ProUni na Faculdade Santo Agostinho. 2010. Dissertação (Mestrado Profissional em Economia)-Pós-Graduação em Economia, Universidade Federal do Ceará, Fortaleza, 2010.

LOPES, F. L.; VENDRAMINI, C. M. M.; MATA, A. S. Diferenças de desempenho acadêmico entre universitários com diferentes tipos de bolsas de estudo. In: JORNADA CIENTÍFICA E SEMANA DE PSICOLOGIA, 2., 2009, Itatiba, SP. Pôster apresentado na Universidade São Francisco.

MCGREW, K. S. CHC theory and the human cognitive abilities project: Standing on the shoulders of the giants of psychometric intelligence research. Intelligence, v.10, n. 1016, p. 1-10, 2008.

MCGREW, K. S.; EVANS, J. J. Internal and external factorial extensions to the Cattell-Horn-Carroll (CHC) - Theory of Cognitive Abilities: A review of fator analytic research, 2004. Disponível em: <http://www.iapsych.com/HCARR2.pdf>. Acesso em: 23 ago. 2010.

PILATI, R.; LAROS, J. A. Modelos de equações estruturais em psicologia: conceitos e aplicações. Psicologia: Teoria $e$ Pesquisa, Brasília, v. 23, n. 2, p. 205-216, 2007.

ROLFHUS, E. L.; ACKERMAN, P. L. Assessing individual differences in knowledge: knowledge, intelligence, and related traits. Journal of Educational Psychology, v. 9, n. 3, p. 511-526, 1999.

SARAIVA, L. A. S; NUNES, A. S. A efetividade de programas sociais de acesso à educação superior: o caso do ProUni. Revista de Administração Pública, v. 45, n. 4, p. 941-964, 2011.

SCHWEIZER, K. Some Guidelines Concerning the Modeling of Traits and Abilities in Test Construction. European Journal of Psychological Assessment, [S.1.], v. 26, n. 1, p. 1-2, 2010.

ULLMAN, J. B. Structural Equation Modeling. In: TABACHNICK, B. G.; FIDELL, L. S. (Org.). Using multivariate statistics. $5^{\text {th }}$ ed. Boston: Pearson Education, 2007.

Recebido em: 21 de novembro de 2012 Aceito em: 5 de novembro de 2015 